\title{
Mulheres na maturidade: histórias de vida e queixa depressiva ${ }^{1}$
}

\author{
Isalena Santos Carvalho \\ Vera Lúcia Decnop Coelho \\ Universidade de Brasília
}

\begin{abstract}
Resumo
O presente trabalho buscou investigar a queixa depressiva em mulheres na maturidade, a partir de eventos significativos ao longo de sua história de vida. Foram realizadas entrevistas clínicas com nove mulheres com diagnóstico de depressão. A análise das entrevistas indicou que as participantes enfrentaram situações de perda ou abandono dos pais, humilhações e maus-tratos, bem como privações econômicas em sua infância, que tiveram impacto sobre sua saúde física e mental. Já na vida adulta, algumas perderam filhos prematuramente. Há casos de violência conjugal. A queixa depressiva parece estar também relacionada a imagens autodepreciativas sobre o exercício dos papéis de mãe e esposa, com sentimentos de culpa e fracasso. O estudo aponta a necessidade de atenção clínica à história de mulheres que apresentam sintomas depressivos na maturidade. Indica-se ainda a discussão da categoria gênero na área da Saúde Mental, para a revisão de concepções históricas e culturais sobre o ciclo de vida feminino.
\end{abstract}

Palavras-chave: mulheres; maturidade; depressão; história de vida

\begin{abstract}
Mature women: life histories and depressive complaints. The present study investigated depressive symptoms in mature women, based on significant events in their life history. Clinical interviews were carried out with nine women diagnosed with depression. The data analysis showed that participants had experienced parents' loss or abandonment, humiliations, ill-treatment, and were financially deprived during their childhood. Such events had a profound impact on their physical and mental health. As adults, some women have lost their children prematurely. There are also cases of marital violence. Depressive complaints seem to be related to low self-esteem images concerning their role as mothers and wives, with feelings of guilt and failure. The study, points out the need of clinical care related to the history of mature women facing depressive symptoms. It is also suggested a discussion of gender category in the field of Mental Health, in order to review historical and cultural concepts of women's life cycle.
\end{abstract}

Keywords: women; maturity; depression; life’s history

${ }^{6} \mathrm{~F}$ alar sobre a depressão na mulher é um pleonasmo”. Este comentário, e outros similares, que por vezes ouvimos em nosso percurso na área de Saúde Mental nos remete a uma associação aparentemente esperada entre a trajetória de vida das mulheres e a depressão. Em referência à faixa etária das mulheres que estudamos - entre 40 a 60 anos - esta associação freqüentemente é descrita como algo ainda mais previsível em função de mudanças hormonais e na auto-imagem feminina relacionadas à menopausa.

Ainda que a depressão seja muito freqüente nas mulheres (Organização Mundial da Saúde/OMS, 2001), parece haver ainda no cenário brasileiro uma carência de serviços na rede pública de saúde (Mori, 2003), bem como de pesquisas destinadas àquelas fora do período reprodutivo, o que evidencia a importância de estudos sobre a maturidade feminina
(Diniz \& Coelho, 2005). Este quadro pode contribuir para uma visão social estereotipada das queixas clínicas que as mulheres enfrentam nessa etapa do ciclo vital, como a presença de sintomatologia depressiva, assunto que desperta controvérsias (Carvalho, 2004; Coelho \& Diniz, 2003).

Nessa perspectiva, buscou-se identificar, através da realização de entrevistas clínicas individuais, eventos significativos na história de vida de mulheres na maturidade que possam estar relacionados à queixa depressiva apresentada em tal período, adotando-se como enfoque para a discussão dos depoimentos colhidos a relação entre gênero e saúde mental. No processo de avaliação diagnóstica da mulher com queixa depressiva na maturidade, é preciso colocar-se em questão concepções históricas e culturais que permeiam o desenvolvimento de homens e mulheres (OMS, 2001; Woollett \& Marshall, 2001). Deve-se questionar, ainda, que com a 
popularização, e, por vezes, banalização do termo depressão, é como se a queixa depressiva por si só justificasse o diagnóstico. Não raro, tende-se a atribuir pouca relevância à singularidade das histórias de vida.

\section{Sintomas depressivos e papéis de gênero}

Uma perspectiva naturalizante e determinista dos modos de interação social e de adoecimento de mulheres e homens parte do pressuposto de que o sexo define os comportamentos tidos como masculinos e femininos. A investigação científica sobre gênero requer uma análise das relações entre homens e mulheres como formulações de uma rede que integra, além da biologia, significados sociais, culturais e psicológicos sobre as identidades sexuais (Diniz \& Coelho, 2005).

A Psicologia, assim como outras áreas do conhecimento, sofreu influências de construções históricas e culturais acerca da trajetória de vida das mulheres. Portanto, como área de produção de conhecimento também precisa rever seus pressupostos acerca dos papéis de gênero. $\mathrm{O}$ debate sobre esta categoria é, em geral, ignorado na pesquisa psicológica, pois, freqüentemente, utiliza-se o termo gênero no lugar de sexo para se demonstrar que foram entrevistados homens e mulheres (Diniz, 1999).

Para Diniz (1999), "uma vez que gênero é aprendido, transmitido ao longo das gerações e incorporado pelas diversas instituições sociais, esse aprendizado resulta em estilos, orientações e experiências distintas do mundo para homens e mulheres” (p. 183). As demandas masculina e feminina decorrentes de tal aprendizagem têm impacto tanto no nível individual - como o funcionamento psicológico, o desenvolvimento físico, as relações interpessoais - como no nível social, ao influenciar as ações político-sociais que são implementadas para responder a essas demandas.

Segundo relatório sobre a saúde mental no mundo da OMS (2001), a prevalência geral de transtornos mentais e comportamentais não parece ser diferente entre homens e mulheres. No entanto, os transtornos de ansiedade e depressivos, são mais comuns no sexo feminino, ao passo que os devido ao uso de substâncias são mais presentes no sexo masculino. Praticamente todos os estudos avaliados pelo relatório mostraram uma prevalência maior de transtornos depressivos e de ansiedade entre mulheres, observando-se usualmente uma razão de 1,5:1 a 2:1.

Nesse relatório, foram apontadas algumas razões para a prevalência de transtornos depressivos nas mulheres. Considerou-se não haver "dúvida de que fatores genéticos e biológicos desempenham algum papel, como o indica particularmente o estreito relacionamento temporal entre uma prevalência mais alta e a faixa de idades produtivas com as alterações hormonais associadas" (OMS, 2001, p. 71). A OMS indica que fatores psicológicos e sociais também pesam significativamente na diferença entre homens e mulheres na prevalência da depressão. É possível que haja mais estressores tanto reais quanto percebidos entre as mulheres. O papel tradicional por elas desempenhado na sociedade expõe as mulheres a um stress mai- or, o que também as torna menos capazes de mudar o seu ambiente gerador de tensão.

Mudanças hormonais somadas à falta de suporte familiar e social, a classe socioeconômica e a situação empregatícia são fatores que podem precipitar a depressão em momentos cruciais da vida da mulher, como, por exemplo, durante a gravidez, o puerpério e a menopausa. Além disso, as mulheres podem ser mais suscetíveis à constituição de transtornos depressivos por ser crescente o número de famílias monoparentais por elas chefiadas, situação em que à ausência de suporte do companheiro para o cuidado dos filhos é associada à longa jornada de trabalho dentro e fora de casa (Diniz, 1999).

Outra razão considerada como favorável às diferenças sexuais nos transtornos mentais é a alta taxa de violência doméstica e sexual a que as mulheres estão sujeitas. Ocorre violência doméstica em todas as regiões do mundo e elas tendem a arcar com a maior parte da sua carga. Em relação à violência sexual, já se estimou que uma em cinco mulheres sofre estupro ou tentativa de estupro durante a sua vida. Essas ocorrências traumáticas têm conseqüências psíquicas, sendo as mais comuns os transtornos depressivos (OMS, 2001, 2002). Deve-se observar, portanto, uma gama de fatores que se intercruzam na vida das mulheres de modo a se obter uma avaliação mais precisa dos sintomas depressivos apresentados.

Essas considerações preliminares sobre desafios e dificuldades socioculturais que permeiam o ciclo de vida da mulher - sobretudo nas últimas décadas, quando houve um aumento da entrada feminina no mercado de trabalho - com implicações em sua saúde mental na maturidade são necessárias para que se possa investigar como esta fala sobre a depressão. Desse modo, pode-se adquirir uma compreensão mais ampla sobre como experiências significativas ao longo de seu desenvolvimento contribuem para a queixa depressiva que apresentam neste momento de vida a fim de se fornecer subsídios ao psicólogo clínico e a outros profissionais da saúde que trabalham com essa população. Tendo por base tais pressupostos, são apresentados a seguir os passos metodológicos do estudo.

\section{Método}

\section{Participantes}

Participaram do estudo nove mulheres entre 40 e 60 anos, de baixa renda, em atendimento psiquiátrico ambulatorial com diagnóstico de depressão, segundo os critérios da CID-10. Os fatores de exclusão ao estudo foram: suspeita de retardo mental, transtornos psicóticos, demenciais ou devidos ao uso de substância.

\section{Local do estudo}

A pesquisa foi realizada na cidade de Brasília, com usuárias do Ambulatório de Psiquiatria do Hospital Regional da Asa Norte (HRAN). O projeto de pesquisa foi submetido à direção da instituição e apreciado pelo Comitê de Ética da Secre- 
taria de Estado da Saúde do Distrito Federal. Os dados foram coletados de março a setembro de 2003.

\section{Estratégias de investigação e procedimentos}

As estratégias de investigação utilizadas em sua ordem de execução foram: (1) aplicação do Inventário Beck de Depressão e entrevista clínica individual; (2) Intervenção psicológica grupal; e, (3) Entrevista individual pós-grupo. No presente trabalho, são discutidos somente os depoimentos obtidos através da entrevista clínica individual.

Como diretriz do roteiro da entrevista clínica, foi empregado o modelo de história pessoal, ou anamnese. Este modelo, segundo Cunha (2000), pressupõe uma reconstituição da vida do paciente, como um marco referencial em que a problemática atual se enquadra e ganha significação. Como eventualmente o paciente não consegue determinar o início de sua queixa atual, é necessário examinar sua história pessoal, de maneira a identificar quando ou como começaram a se delinear dificuldades ou a se evidenciar comprometimentos em uma ou mais área de funcionamento social, profissional, acadêmico, etc. Com a adoção desse modelo, desenvolveu-se um roteiro de entrevista semi-estruturada, o qual foi dividido nos seguintes blocos: variáveis sociodemográficas; história da queixa clínica atual; antecedentes psicopatológicos pessoais e familiares; desenvolvimento biopsicossocial nos períodos da infância, adolescência, adulto jovem e maturidade; dinâmica conjugal anterior e atual; e, concepções sobre a depressão.

Para a realização do estudo, foi solicitado aos profissionais do Ambulatório de Psiquiatria do referido hospital o encaminhamento de usuárias que atendessem aos critérios estabelecidos. Após o encaminhamento, eram esclarecidos a cada participante os objetivos e as etapas da pesquisa, com a leitura e a assinatura do Termo de Consentimento Livre e Esclarecido. Seguia-se, então, a realização da entrevista clínica individual, que durava, em média, duas horas.

\section{Referencial de análise do material}

As entrevistas foram transcritas e analisadas de acordo com a proposta hermenêutico-dialética. Esta proposta desenvolveu-se a partir de um debate entre Jüergen Habermas e Hans-George Gadamer, na década de 60, acerca da relação entre teoria e práxis na pesquisa. Este debate beneficiou as discussões sobre metodologia qualitativa, na medida em que esses autores buscaram formas de atingir a objetividade da pesquisa pautada na práxis. A complementaridade entre a hermenêutica e a dialética parte do pressuposto de que não há pesquisa imparcial, nem ponto de vista fora da história. Entretanto, a análise hermenêutica-dialética não deve ser reduzida a simples teoria de tratamento de dados. Esta análise é indicada como um caminho do pensamento que se constitua, ao mesmo tempo, enquanto compreensivo e crítico da realidade social na condução do processo de discussão dos dados (Minayo, 1993).

Visando atender tal proposta, constituiu-se o corpus da pesquisa com base na leitura exaustiva das entrevis- tas. As categorias temáticas de análise foram definidas a partir da identificação dos eventos recorrentes na fala das participantes.

\section{Resultados e discussão}

As nove entrevistas foram analisadas em conjunto. Para a elaboração das categorias temáticas, foi realizada uma reconstrução das histórias de vida narradas, da infância à fase adulta jovem. Na reconstrução, buscou-se identificar eventos que podem estar relacionados à queixa depressiva apresentada na maturidade, segundo a perspectiva das participantes e inferências feitas pelas autoras. Eventos da maturidade, também possivelmente associados à sintomatologia depressiva manifestada pelas mulheres neste momento de vida, serão abordados em artigo subseqüente. Ressalta-se que os nomes utilizados são fictícios.

\section{Perdas e privações na infância}

É importante observar o impacto de condições socioeconômicas sobre a história de vida pessoal, bem como sobre a saúde física e mental. Conforme Muraro (1996), a noção de perda não é a mesma para cada classe social. As perdas ao longo do desenvolvimento também se articulam segundo as condições econômicas. Estas condições influenciaram significativamente o desenvolvimento infantil das participantes, o qual foi marcado por anos de restrições.

Doze dias antes de Rute nascer, seu pai faleceu. Sua mãe, não suportando a morte do marido, morreu seis meses depois. Durante anos, Rute se responsabilizou pela morte da mãe, acreditando que esta havia decorrido de complicações no parto. Isaura, por sua vez, perdeu o pai aos 12 anos. Como sua mãe considerou que não conseguiria cuidar dos filhos, da casa e da "roça" sozinha, a família mudou-se para o Distrito Federal, onde Isaura começou a trabalhar como empregada doméstica.

É provável que essa situação de perda dos pais agrave outras privações cotidianas nas classes socialmente menos favorecidas. Nessas, a ausência das figuras materna e/ou paterna pode contribuir para que a menina mais rapidamente seja considerada como alguém que deve assumir as responsabilidades domésticas, o que não tende a ocorrer em famílias com maior poder aquisitivo (Holland, 1994). Outras participantes, ainda que não tivessem sofrido a morte de um dos pais na infância, relataram situação de abandono paterno e/ou materno. Assim, foram criadas por outras pessoas, nem sempre seus familiares, muitas vezes sem cuidados básicos e sem afeto. No relato abaixo, Helena nos fala do abandono materno.

Acho que quando eu tava crescendo o meu maior sofrimento era primeiro: abandono da mãe, porque ela me deixou com três anos de idade, eu tava no começo do crescimento, dava falta de carinho, de atenção e tudo mais, né? E hoje eu sou mãe e sei o que é isso, né? E o sofrimento que eu passei lá, de saber que eu tinha uma mãe que tinha condição, que na época ela tinha condição - e hoje ela não tem, hoje ela vive comigo - que tinha condição, mas que eu tava lá jogada na mão dos outros. 
Hoje, conforme suas palavras, sendo mãe e sabendo o que é isso, Helena se ressente da falta de um vínculo necessário ao seu desenvolvimento. Tendo sido criada por sua família paterna, era constantemente maltratada e humilhada. Na época, considerava que era "melhor morrer" a continuar sofrendo abusos.

Norma, por sua vez, relatando ser "filha de mãe solteira”, observou que se tivesse recebido a assistência necessária de seu pai, não teria desenvolvido uma deficiência genética visual. Sem a devida orientação, já adulta, sofreu um acidente automobilístico que agravou sua deficiência. Devido ao acidente, perdeu aproximadamente $80 \%$ da visão, o que provocou sua saída do emprego como telefonista. Por ocasião da entrevista, Norma estava movendo um processo na justiça “para ser reconhecida” por seu pai. Ela desejava obter, além de uma ajuda financeira através da qual pudesse arcar com as despesas da cirurgia dos olhos, o direito a um sobrenome que lhe foi negado face à situação de abandono. Com a ausência do sobrenome paterno, sentia-se expropriada de um direito que socialmente é conferido pela autoridade masculina (Holland, 1994).

Segundo Cunha (2000), para se compreender a queixa clínica atual é necessário que se investigue como foi a qualidade da relação entre a criança e seus responsáveis, bem como as estratégias desenvolvidas por ela para lidar com mudanças e crises sofridas ao longo de sua vida. Os acontecimentos também devem ser compreendidos em função do contexto em que ocorreram.

Além da ausência da mãe e/ou do pai relatada por algumas, as participantes, em geral, cresceram em um contexto marcado por privações socioeconômicas. Começavam a trabalhar logo que desenvolviam condições físicas e cognitivas. O ingresso tardio na escola ou a evasão escolar eram esperados frente à necessidade de arcar com o próprio sustento e o sustento familiar. Assim nos diz Isaura:

Minha mãe preferia que a gente trabalhasse mais na roça do que estudasse. As minhas irmãs mais velha teve estudo mais do que eu, né? Inclusive, eu vim pra Brasília, ela [mãe] ficou viúva, eu tinha doze anos. (...) Aí eu fiquei com ela, vim pra Brasília e tive que começar a trabalhar de doméstica pra ajudar ela nas despesas de casa, né? Não tive como estudar mais porque antigamente os patrão não deixava sair à noite pra estudar.

Isaura relaciona sua dificuldade em freqüentar a escola às proibições de sua mãe e dos “patrões”. Trabalhar e estudar eram atividades excludentes. Sem poder continuar seus estudos, sente dificuldade para ler e escrever. Vilma, por sua vez, como não pôde estudar, hoje se queixa da forma como é tratada por sua "patroa”, que, com uma certa freqüência, a lembra que se perder o emprego de doméstica, dificilmente conseguirá outro por estar envelhecendo e ser "analfabeta”.

Com as perdas sofridas ao longo da infância e adolescência, as mulheres, em geral, revelavam uma nostalgia de pessoas e de oportunidades que não chegaram a conhecer. Precisando trabalhar desde a infância, destacaram a falta de tempo para ser criança. Da infância para a vida adulta jovem houve uma transição extremamente rápida. O evento que marcava esta passagem era a menarca. No momento em que começava a sangrar, a menina se tornava mulher pela consideração de que a partir de então poderia procriar. Assim, ela deveria aprender, por vezes sozinha, a lidar com as implicações desse novo status social. Conforme veremos no tópico seguinte, esta transição foi perpassada por muitos silêncios acerca de importantes etapas do ciclo vital feminino.

\section{A educação feminina e o silêncio}

Os valores investidos sobre a sexualidade de homens e mulheres variam de acordo com sua classe social. Segundo Muraro (1996), a percepção do corpo está estreitamente articulada às dificuldades enfrentadas por cada classe social. Nos depoimentos, percebe-se que o conhecimento do corpo próprio foi marcado por uma série de silêncios acerca da menarca, crescimento dos seios, primeira relação sexual, gestação, parto e maternidade, dentre outros eventos, conforme se pode observar na fala de Leila:

Eu nem sabia o quê que era; eu entrei no quarto quando eu fui tirar a minha roupa, eu vi aquele sangue, eu pensei que eu mesma tinha me furado, sem orientação... Aí me tranquei no quarto e comecei a chorar. Aí a mãe foi lá, bateu na porta e perguntou porque que eu estava chorando. Aí minha mãe pensou que eu tinha perdido a virgindade. Aí eu disse assim: 'Não, mãe, tá saindo esse negócio aí’. Não falava nada, eu também não sabia.

De acordo com Giddens (1993), a vergonha é uma característica mais acentuada na educação das mulheres. Já na infância, a menina aprende que os eventos relacionados a seu corpo precisam ser encobertos. Falar sobre sua sexualidade é torná-la evidenciada, o que deve ser evitado. Sem as informações necessárias, muitas mulheres identificavam as transformações em seu corpo com vergonha, o que dificultava a busca de esclarecimentos sobre tais assuntos junto aos familiares. Trabalhos realizados com grupos de mulheres na maturidade vêm confirmando esta realidade (Coelho \& Diniz, 2003; Diniz \& Coelho, 2005). O desconhecimento e constrangimento da mulher em relação ao seu corpo atravessam as etapas do seu ciclo de vida (Mori \& Coelho, 2004), o que tende a contribuir para o aumento de dúvidas, receios e sofrimentos acerca do lugar que passa a ocupar na sociedade à medida que envelhece.

A maioria das participantes casou-se durante a adolescência, vindo a ter filhos logo depois. Sem a oportunidade de estudar devido às dificuldades econômicas familiares, o casamento era muitas vezes percebido como possibilidade de se adquirir um pouco de liberdade e de satisfação pessoal. Isaura, por exemplo, decidiu fugir de casa para se casar. A mãe não autorizava o casamento da filha já que esta era o "braço direito” junto aos irmãos menores. Precisou fugir para conquistar outras possibilidades para sua vida.

Leila descreveu o pensamento que teve quando decidiu se "juntar" com seu primeiro parceiro sexual: "Se eu ficar com ele, eu vou ter liberdade pra mim poder sair, pra mim poder ir 
embora daqui. Ter um outro mundo, ver um outro mundo". Considerava que poderia se manter sozinha em outra cidade. Contudo, após a perda da virgindade, com receio de se tornar "prostituta", concluiu que precisaria morar com o namorado para não ser difamada. Leila nos aponta uma realidade vivida por inúmeras mulheres de classes menos favorecidas, hoje na maturidade. Para serem valorizadas e respeitadas, precisavam casar-se (Diniz \& Coelho, 2003).

As restrições impostas pelas condições econômicas e culturais ainda contribuem para que as mulheres identifiquem o casamento e a maternidade como seu principal meio de reconhecimento social. Apesar das modificações no âmbito familiar, provocadas, dentre outros aspectos, pela maior presença da mulher no mercado de trabalho, o espaço doméstico continua a ser considerado como predominantemente feminino. Em geral, espera-se que esta cuide dos filhos e da casa, sem questionar as dificuldades inerentes a essas funções. No próximo tópico, discute-se como a maternidade era muitas vezes sentida como um peso em função das responsabilidades que representa.

\section{Dilemas na maternagem}

Ao se tornarem mães, as mulheres podem ter dificuldade em reconhecer seus sentimentos ambivalentes em relação aos filhos e sua criação. Receiam ameaçar a imagem de "boa mãe", à qual esperam corresponder. Quando não cumprem tal expectativa, tendem a se culpar pelas dificuldades que os filhos apresentam durante seu desenvolvimento (Woollett \& Marshall, 2001).

Nicolson (conforme citado por Woollett \& Marshall, 2001) observou que, em geral, os sentimentos ambivalentes da mulher sobre a maternidade são considerados como problemáticas pessoais sem relação com o contexto social no qual ela está inserida. A pouca informação e a ausência de assistência podem ser percebidas pela mulher como uma realidade individual, com a qual precisa arcar sozinha. Na medida em que não se dá conta de que essa situação é comum a outras mulheres, que também carecem de suporte familiar e social, seu sofrimento tende a ser maior, o que pode contribuir para a ocorrência e agravamento de sentimentos categorizados na literatura médica como sintomas depressivos, a exemplo da culpa e da autodepreciação.

Ao se casarem, diversas mulheres tinham de aprender por conta própria a criar os filhos. Sem assistência e inexperientes nessa tarefa, algumas se culpavam pela morte prematura deles. Consideravam, como nos diz Norma, que sua "depressão" seria em parte decorrente de sua incapacidade para cuidar de uma criança:

eu me sinto culpada pela morte dele, porque eu era muito criança. Não é a questão de ser criança, porque hoje aí as meninas com 12, com filho no colo e sabe cuidar. É porque eu era muito boba, assim aquela pessoa que não existe mais. Hoje não existe aquelas pessoas, tampada, boba. Então, olhando pra trás, de repente eu tive um pouco de culpa, que ele morreu de desidratação. Então você vê, uma coisa que era um pouco mais de cuidado, né?
Tendo casado adolescente, Norma considerava que não havia aprendido a cuidar de si, muito menos de uma criança. Embora reconhecesse que lhe faltara apoio, culpava-se por não ter sido uma mãe "melhor”. Para Giddens (1993), no desenvolvimento do psiquismo das mulheres a culpa ocupa um lugar de destaque. Esse sentimento se torna de tal modo atrelado ao exercício de papéis femininos que a mulher tende a se considerar a principal responsável pela criação dos filhos. Ela sente que deve zelar pelo bem-estar desses, ainda que suas necessidades pessoais fiquem em segundo plano. A culpa se revelaria nas situações de convivência diária, como Leila nos aponta:

Então eu botei aquilo na cabeça né, que eu puni... eu me sinto punida, que eu to sendo punida por ter deixado meus filhos àtoa e Deus me castigou, por isso que tirou meu filho. De eu ter deixado eles à-toa pra ir trabalhar, tentar uma nova vida, tentar a vida, a ter outras coisas dentro de casa, porque não tinha nada.

Embora Leila relatasse que precisou trabalhar fora de casa para prover o sustento dos filhos, culpava-se pelo envolvimento desses, quando adultos, com "maconha" e "bebida". A morte do filho mais velho era considerada como punição por ela necessitar ausentar-se do ambiente familiar. Ao avaliar suas motivações para começar a trabalhar, a culpa por não ter acompanhado o crescimento dos filhos sobrepujava seus esforços para propiciar melhores condições de vida à família.

Um dos principais aspectos da história de vida das participantes associados à depressão foi a dificuldade em cuidar dos filhos e uma ausência de êxito decorrente desse cuidado. Algumas, após a separação conjugal, criaram os filhos sozinhas. Outras, embora contassem com a presença do parceiro, também percebiam estar sós para criá-los. Dentre aquelas que criaram os filhos sem um parceiro, Helena relata o que sentiu na época:

Eu dizia assim pra mim mesmo, mentalmente, né? Que eu ia ficar doida, que eu não ia conseguir sustentar aquelas meninas, que eu não ia criar aquela menina, ficar no meio da rua, eu e as meninas e tudo mais. Então tudo isso acarretou, pra... tudo isso acarretou pra causar a depressão, porque eu não sabia o que quê era. Pra mim, era assim pelo jeito, nervosismo. (...) assim tudo na minha vida era chorar, chorar, chorar.

Helena considerava que havia tido depressão por não saber como cuidar de suas filhas após a separação. Para Woollett e Marshall (2001), torna-se mais difícil às mulheres sem um parceiro exercer o que seria considerado culturalmente como uma boa maternagem. Segundo os autores, elas provavelmente têm menos recursos financeiros e residem em locais que oferecem condições pouco adequadas de assistência. Seus filhos terão menos chances de estudar em escolas de qualidade. Apesar disso, Helena considera que a necessidade de trabalhar para que suas filhas não "mendigassem na rodoviária" contribuiu para ela "melhorar" da depressão.

Norma vivenciou uma situação similar à de Helena, receando não conseguir sustentar os filhos após a separação 
conjugal. Na ocasião, pensou em cometer suicídio por envenenamento, o que não ocorreu pela intervenção do filho mais velho. Decidiu que não iria se matar porque os filhos precisavam de seus cuidados. Estes casos sugerem que a vivência de incapacidade de lidar com a situação de sustento dos filhos, provavelmente associado ao luto decorrente do fracasso da relação conjugal, pode ter contribuído para o desencadeamento de um quadro depressivo. Somente Helena procurou assistência médica na época, tendo, tal como agora na maturidade, estado sob acompanhamento psiquiátrico.

Embora Leila e Magnólia tenham contado com a presença de um parceiro, também se sentiam sós na criação dos filhos. Sem respaldo emocional e financeiro, ainda eram criticadas pelo modo como educavam os filhos. O marido de Leila, por exemplo, lhe dizia constantemente: "Você não tem moral pra criar teus filhos".

Noções culturais sobre a maternidade têm impacto sobre todas as mulheres, mesmo as que não tiveram filhos. Culturalmente consagrada na maternidade, a mulher vê-se impelida a realizar a maternagem de irmãos mais novos e sobrinhos. Assim, arca com as responsabilidades inerentes a esse papel, ainda que, muitas vezes, não haja um reconhecimento de seus esforços. É possível concluir que as funções que a mulher tradicionalmente desempenha não tendem a ser socialmente valorizadas. Entre as participantes, a aprendizagem de eventos relacionados ao feminino ocorreu sem o necessário esclarecimento e suporte às suas dúvidas. Na seção seguinte, as implicações desse quadro podem ser percebidas na relação conjugal.

\section{Sentimento de fracasso conjugal e violência perpetrada por parceiro íntimo}

Algumas participantes ressaltaram um sentimento de fracasso por não conseguirem manter uma relação conjugal satisfatória. Norma e Helena, por exemplo, atribuíam o término do casamento à sua exclusiva responsabilidade. A falta de êxito em atender às necessidades masculinas justificaria a traição e, conseqüentemente, a separação conjugal.

Norma, após sofrer um acidente de automóvel, que agravou uma deficiência genética visual, passou cerca de um ano e meio hospitalizada. Ao retornar para casa, seu marido pediu-lhe que encontrasse um lugar para morar porque já estava vivendo com uma outra mulher. Norma acreditava que se não tivesse ficado revoltada com a situação, seu casamento não teria terminado.

Vinte e três anos de casado, ele era um todo para mim, eu não tenho pai, só tenho mãe lá no interior. Então eu investi muito nele. Na época que eu soube que ele tava com outra, aí eu fiquei... entrei em parafuso mesmo. Eu fui muito insuportável, brigava, xingava, tornava a casa um horror e por isso talvez que eu me sinto culpada, porque se eu fosse um pouco mais compreensiva, fazer de não ver, de não sentir, não olhar, de repente tinha chegado a algum acordo em comum. De repente não tinha nem separado, né? Se eu fosse mais compreensiva. E talvez meus filhos que estudavam em colégio particular, que tinha uma vida bem melhor não taria como estar, né? Então tá aí a minha culpa, né?

Subjacente à autodepreciação descrita por Norma, encontra-se o que considera ser o papel de uma boa esposa: não questionar. Ao demonstrar seu incômodo face à traição, acreditava ter possibilitado a separação. Norma se culpava por não ter sido o ideal de esposa que havia projetado ser durante sua infância. Após a separação, tinha dificuldades em estabelecer outros projetos para si. Ressentia-se por não ter conseguido manter o casamento e, portanto, fracassar como mulher. Acreditando que não tinha mais o que oferecer aos outros e, sobretudo, a si própria, não reconhecia mais seu valor.

Norma não sabia como buscar outros referenciais para si, além dos que recebeu como o de ser uma "esposa compreensiva”. Com as modificações ocorridas após o acidente, o passado era descrito como a melhor época de sua vida. Havia uma dificuldade concreta, imposta pela degeneração visual, e simbólica, de perceber outras possibilidades de significação de suas relações e projetos de vida.

Helena, por sua vez, ao relatar o que caracterizava como sua dependência do marido, também se retratava em um lugar de menos-valia. Nessa posição, era estabelecido o pressuposto de um constante débito a esse outro, o parceiro, identificado como o detentor do poder hierárquico na união conjugal. A autoridade masculina parecia justificar que o marido utilizasse o que é denominado, segundo a OMS (2002), como violência psicológica perpetrada por parceiro íntimo - intimidação, constante desvalorização, humilhação. Embora através de insultos e traições Helena se visse depreciada como mulher, sentia que não lhe restava outra opção a não ser submeter-se. Terminar o casamento implicaria que ela falhou em se conformar às exigências conjugais.

Para Muraro (1996), a influência do modelo patriarcal sobre a família contribui para que as mulheres continuem a ser subjugadas pela dominação masculina, que é sentida sobre seu corpo. Conforme a autora, é na materialidade do corpo das mulheres que todos os poderes e desprazeres se cruzam. Holland (1994) esclareceu que a dominação sobre o corpo tende a ser percebida como uma expropriação pelas vítimas da violência conjugal. Com a expropriação do corpo, a ocorrência de sentimentos como a humilhação tende a contribuir para que a mulher apresente uma baixa auto-estima. Isto favorece a constituição de sintomas depressivos em etapas posteriores da vida.

Uma das formas mais comuns de violência contra as mulheres é a praticada por parceiro íntimo (OMS, 2002). O fato de as mulheres, em geral, encontrarem-se emocionalmente envolvidas com os parceiros que as vitimizam e dos quais dependem economicamente, tem grandes implicações sobre a dinâmica do abuso, o qual pode ser: físico, sexual e psicológico. A OMS indicou que, apesar dos estudos sobre a violência de gênero se concentrarem no abuso físico, para muitas mulheres o abuso psicológico é ainda mais intolerável.

As justificativas culturais para a violência conjugal geralmente decorrem de noções tradicionais sobre os pa- 
péis característicos de homens e mulheres. Estas noções estabelecem que as mulheres devem cuidar dos filhos e de seus lares, mostrando obediência aos maridos. Se um homem considerar que a mulher não cumpriu seu papel ou ultrapassou os limites, pode utilizar a violência como resposta (OMS, 2002). A mulher fica, assim, exposta a uma situação de violência perpetrada por uma das pessoas que lhe é mais cara em seu ambiente familiar e em sua vida. A ambigüidade é configurada quando o parceiro, que supostamente deveria zelar pelo seu bem-estar, é quem a mantém subjugada física, psicológica e sexualmente. No relato a seguir, Magnólia descreve como era seu convívio com o parceiro durante aproximadamente vinte anos: "Foi péssimo, porque ele era muito agressivo, sabe? Uma pessoa muito difícil de conviver, sabe? Me ameaçava muito. (Ele te batia?) Só quando ele bebia. Aí ele me batia. (E ele bebia freqüentemente?) Bebia”.

Um dos motivos que a fez se separar foi sua filha, já adulta, lhe dizer: "Mãe, o pai não vai mudar". Com a imposição do marido de que só não seriam expulsas de casa se ela continuasse a acatar as ordens dele, Magnólia decidiu mudar-se para o Distrito Federal, onde esperava não mais viver sob constante ameaça. Como a filha já tinha condições de se manter por conta própria, sentiu-se liberada para sair desse ambiente marcado pela violência.

A violência conjugal, fato presente na vida de muitas mulheres, retira não só seu direito enquanto cidadãs - como o direito de ir e vir - mas o domínio sobre o seu próprio corpo. Com a expropriação do corpo, muitas se calam face à violência sofrida pelo receio de que a denúncia abale o equilíbrio familiar, o que contribui para a manutenção das agressões. Este silêncio pode perdurar por vários anos, trazendo graves prejuízos à saúde física e mental da mulher.

Vilma, ao comentar que nunca sofrera violência sexual de pessoas estranhas, revelou seu mal-estar por ter sido vítima do próprio marido. Relatou que gostaria de ter saído do relacionamento na ocasião; contudo, preferiu permanecer por causa dos filhos.

Olha [violência], dos de fora, não, mas sabe que quando o meu marido era mais novo... Eu não vou nem falar o restante. Eu já sofri. Eu falo pra ele que eu tenho problema de hemorróida até hoje, é por causa dessa covardia que ele me fez. (...) Porque ele me violentou pela parte de trás. É uma mágoa bem grande, muito grande. Porque às vezes eu podia até já ter que sofrer aquilo, mas a minha grande culpa que eu falo foi isso... que aconteceu. Se fosse outra, naquele tempo, eu tinha largado... Se fosse hoje, eu tinha ido embora. Passei, não é agora que eu vou passar as coisas pra trás.

A violência sofrida por Vilma provinha de quem escolhera para ser seu companheiro de vida. Relatou que nunca havia comentado esta situação com alguém. A raiva, a mágoa, a frustração são muitas vezes silenciadas pela mulher para a manutenção dos vínculos familiares. Considerando que o momento de "largar" o marido em função da violência sofrida havia passado, Vilma acreditava que não podia abandoná-lo agora, porque o seu próprio tempo já passara.
Já “velha”, não teria condição de separar-se. Sentia que devia deixar a agressão sexual no passado, mantendo em segredo a violência sofrida.

O sentimento de fracasso conjugal e a situação de violência perpetrada por parceiro íntimo são aspectos que denotam como algumas das participantes tendem a se perceber de um modo pouco favorável. As freqüentes auto-recriminações tornavam difícil a tarefa de identificar um saldo positivo em suas escolhas e realizações ao longo das etapas que antecederam à maturidade. Neste período, esta dificuldade vai ser configurada na queixa depressiva que as motivou a procurar tratamento.

Conforme se pôde perceber, cada sentido relacionado à depressão fundamenta-se na construção de papéis sociais (Castells, 1999). Como propor alternativas às implicações desses papéis sem negligenciar a importância que representam em suas vidas? Este desafio aumenta, conforme os depoimentos, quando se considera que as mulheres aprenderam a atrelar seu valor pessoal à maternidade e ao casamento.

Se a depressão está - ao menos em parte - relacionada às perdas e dificuldades enfrentadas, é preciso conferir crédito ao que vivenciaram em sua trajetória. Sem esse cuidado, o psicólogo no atendimento a mulheres na maturidade com diagnóstico de depressão tende a contribuir para a manutenção de estereótipos e preconceitos relacionados às dificuldades que enfrentam ao longo de seu ciclo de vida, marcadas, não raro, pela ausência de suporte social. Caso favoreça uma necessária acolhida à expressão dessas dificuldades, é possível que se depare com relatos de sofrimentos partilhados após anos ou décadas de segredo.

\section{Considerações finais}

Este estudo teve como principal objetivo ampliar o conhecimento sobre a queixa depressiva em mulheres na maturidade, a partir da identificação de eventos significativos em suas histórias de vida. Para isso, foi fundamental conhecer depoimentos de algumas destas sobre o que é atualmente denominado como o sofrimento psíquico das sociedades contemporâneas - a depressão.

O presente trabalho confirma que eventos significativos ao longo da vida têm implicações sobre a saúde mental da mulher na maturidade, podendo contribuir para a constituição de sintomatologia depressiva (Diniz \& Coelho, 2003; Mori, 2003). Na análise das histórias de vida observou-se que perdas - como morte ou abandono dos pais - ausência de cuidados na infância e dificuldades econômicas, entre outros fatores, tiveram implicações à sua saúde física e mental. A educação que receberam, em geral, foi marcada por silêncios acerca do ciclo de vida feminino. Na adolescência, algumas identificaram o casamento como a possibilidade de conseguir algo que pudessem denominar de seu face às privações cotidianas.

Quando se tornavam mães, tendiam a considerar que a criação dos filhos era de sua inteira responsabilidade. Algu- 
mas perderam os filhos prematuramente por falta de assistência familiar e social. No casamento, por sua vez, sofreram situações que contribuíram para que se depreciassem como mulheres. O casamento era estabelecido, assim, como uma relação hierárquica, na qual cabia ao homem a autoridade sobre o corpo e o desejo da mulher. Esta relação "justificaria” casos de violência conjugal.

Os movimentos feministas contribuíram para que a mulher esteja se tornando mais consciente de que os eventos presentes em sua experiência pessoal têm base em uma estrutura sociocultural compartilhada por outras mulheres. Com esta consciência, ao aceitar os marcos inerentes à especificidade de seu corpo, os quais não se reduzem ao biológico, ela pode superar a definição cultural limitante que lhe foi dada - como a função de procriar (Castells, 1999). Contudo, os relatos nos mostram que há ainda muitos silêncios sobre seu corpo e sobre a violência de que são vítimas. Ainda que adoeçam, tendem a silenciar seus sofrimentos para preservar a dinâmica familiar.

Mesmo as mulheres tendo adquirido, aparentemente, o direito de controlar seus corpos e vidas, os problemas referentes à discriminação, opressão e abuso não foram eliminados, nem sua intensidade foi significativamente reduzida (Castells, 1999). Nesse sentido, a redução da clínica à mera descrição sintomatológica tem como conseqüência a reintrodução das oposições entre o normal e o patológico, originárias do discurso psiquiátrico tradicional. A singularidade das histórias de mulheres com queixa depressiva não deve ser perdida na avaliação dos sintomas apresentados. Sem atenção aos eventos significativos ao longo da vida, sua compreensão sobre as origens do que sente tende a perder importância.

Face à complexidade e à relevância do tema abordado, são necessários outros estudos que possibilitem a escuta das experiências de vida da mulher na maturidade. Sugerese a investigação da presença de sintomas depressivos em mulheres que não estejam sob tratamento psiquiátrico ou outras modalidades de atendimento na área de Saúde Mental para a ampliação da compreensão sobre o tema.

\section{Agradecimento}

As autoras agradecem ao Conselho Nacional de Desenvolvimento Científico e Tecnológico (CNPq), pelo apoio financeiro.

\section{Referências}

Carvalho, I. S. (2004). Do botão à rosa, da rosa à...: um estudo sobre a queixa depressiva em mulheres na maturidade. Dissertação de mestrado nãopublicada, Universidade de Brasília, Brasília.

Castells, M. (1999). A era da informação: economia, sociedade e cultura. O poder da identidade. São Paulo: Paz e Terra.

Coelho, V. L., \& Diniz, G. (2003). Vida de mulher: lidando com a meia-idade e a menopausa. In T. Féres-Carneiro (Org.), Família e casal: arranjos $e$ demandas contemporâneas (pp. 97-117). São Paulo: Loyola.

Cunha, J. A. (2000). A história do examinando. In J. A. Cunha (Org.), Psicodiagnóstico-V (pp. 57-66). Porto Alegre: Artes Médicas.

Diniz, G. (1999). Condição feminina - fator de risco para a saúde mental? Em M. G. T. Paz \& A. Tamayo (Orgs.), Escola, saúde e trabalho: estudos psicológicos (pp. 181-198). Brasília: Editora da Universidade de Brasília.

Diniz, G., \& Coelho, V. (2005). A história e as histórias de mulheres sobre o casamento e a família. In T. Féres-Carneiro (Org.), Família e casal: efeitos da contemporaneidade (pp. 138-157). Rio de Janeiro: Editora da PUC-Rio.

Giddens, A. (1993). A transformação da intimidade: sexualidade, amor e erotismo nas sociedades modernas. São Paulo: UNESP.

Holland, S. (1994). Psicoterapia, opressão e ação social: sexos, raça e classe na depressão de mulheres negras. In R. J. Perelberg \& A. C. Miller (Orgs.), Os sexos e o poder nas famílias (pp. 267-279). Rio de Janeiro: Imago.

Minayo, M. C. S. (1993). O desafio do conhecimento: pesquisa qualitativa em saúde. São Paulo: HUCITEC-ABRASCO.

Mori, M. E. (2003). A vida ou vida: a escuta psicológica e a saúde da mulher de meia-idade. Dissertação de mestrado não-publicada, Universidade de Brasília, Brasília.

Muraro, R. M. (1996). Sexualidade da mulher brasileira: corpo e classe social no Brasil. Rio de Janeiro: Record; Rosa dos Tempos.

Organização Mundial de Saúde (2001). Relatório sobre a saúde no mundo 2001. Saúde mental: nova concepção, nova esperança. Brasília: Gráfica Brasil.

Organização Mundial da Saúde (2002). Relatório mundial sobre violência e saúde. Brasília: Centro de Documentação OPAS/OMS.

Woollett, A., \& Marshall, H. (2001). Motherhood and mothering. In R. Unger (Org.), Handbook of the psychology of women and gender (pp. 170-182). Nova York: Wiley.

${ }^{1} \mathrm{O}$ trabalho é parte da dissertação de mestrado da primeira autora, realizada sob orientação da segunda.

Isalena Santos Carvalho é mestre e doutoranda em Psicologia pela UnB.

Endereço para correspondência: Rua Perdizes, Cond. Versalhes, apt. 302-A, Renascença-II; São Luís, MA; CEP: 65075-340. Telefone: (98) 3227-8341.E-mail: isalenasc@unb.br

Vera Lúcia Decnop Coelho, doutora em Psicologia pela Case Western Reserve University (EUA), é professora aposentada da Universidade de Brasília e pesquisadora associada adjunta no Instituto de Psicologia da mesma instituição.E-mail: vldc@unb.br 